\title{
Color Doppler imaging: An overview
}

\author{
VARTAN N. IGIDBASHIAN, DO \\ DONALD G. MITCHELL, MD \\ DANIEL A. MERTON, RDMS \\ BARRY B. GOLDBERG, MD
}

which allows simultaneous two-

Color Doppler imaging (CDI), dimensional imaging of structure and blood flow, is a recent development in ultrasonography. Detailed information regarding blood flow can be obtained from anechoic spaces on ultrasonographic images, while evaluation with the conventional duplex Doppler method requires interrogation of flow in a limited region of interest. The great advantage of CDI is its ability to depict actual blood flow through vessels. Previously, blood flow could not be visualized directly; it was necessary to opacify the vessel lumen by injecting contrast media. In this paper, the principles of CDI and its various applications are discussed and illustrated.

Real-time, color, flow-mapping devices were first developed and used for cardiac imaging. ${ }^{1,2}$ A color converter assigns color based on the direction and value of detected frequency shifts. ${ }^{3}$ This information is superimposed on a conventional gray-scale ultrasonic image generated from the amplitude of the reflected echoes.

In our system (Quantum Medical Systems, Issaquah, Washington), $7.5-\mathrm{MHz}, 5.0-\mathrm{MHz}$, and 3.0 $\mathrm{MHz}$ linear array transducers are utilized. The 7.5$\mathrm{MHz}$ transducer is used for pediatric imaging as well as for imaging of superficial structures, including the thyroid gland, testicles, breasts, and superficial vessels. The $5.0-\mathrm{MHz}$ and $3.0-\mathrm{MHz}$ transducers are used for abdominal and pelvic imaging, depending on the depth of the area of interest and patient size.

The direction of flow relative to the transducer is displayed in each pixel as either red or blue, depending on whether blood is flowing toward or away from the transducer. An increase in color density represents slower velocities, while increasing flow velocity is displayed as decreased intensity or increased "whiteness" of the color. If possible, the

direction of assignment of red or blue is chosen so that flow in the arteries will be displayed as red and in the veins as blue. If a Doppler spectrum is needed, the appropriate area to be interrogated can be selected easily.

\section{Applications}

Cardiac imaging

Color Doppler imaging (CDI) is most commonly used for cardiac evaluation and has proved to be particularly useful in the assessment of valvular stenosis, valvular insufficiency, and shunt lesions. ${ }^{4,5,6}$ It also has promoted better understanding of complex normal and pathologic flow patterns.

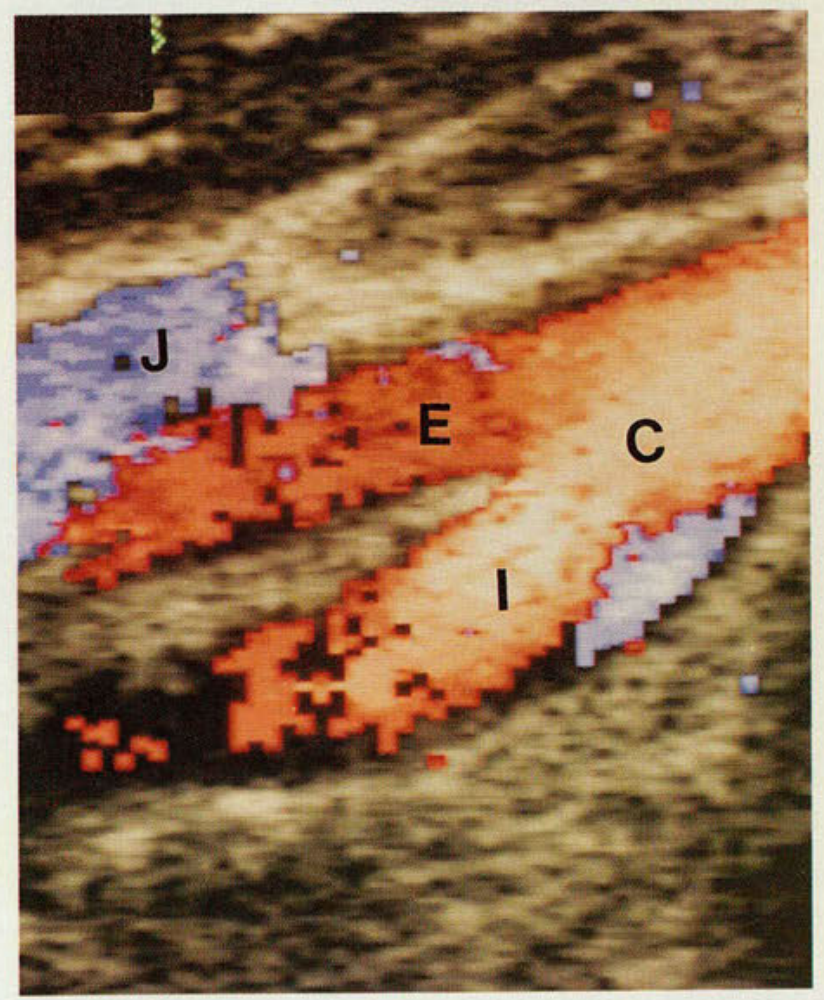

Fig 1. Normal color flow depiction of the common carotid artery (C) and bifurcation. The external carotid artery is shown at E, the internal carotid artery at $I$, and the jugular vein at J. Note normal area of flow separation in blue at the proximal internal carotid artery. This is the most common location for plaque. 


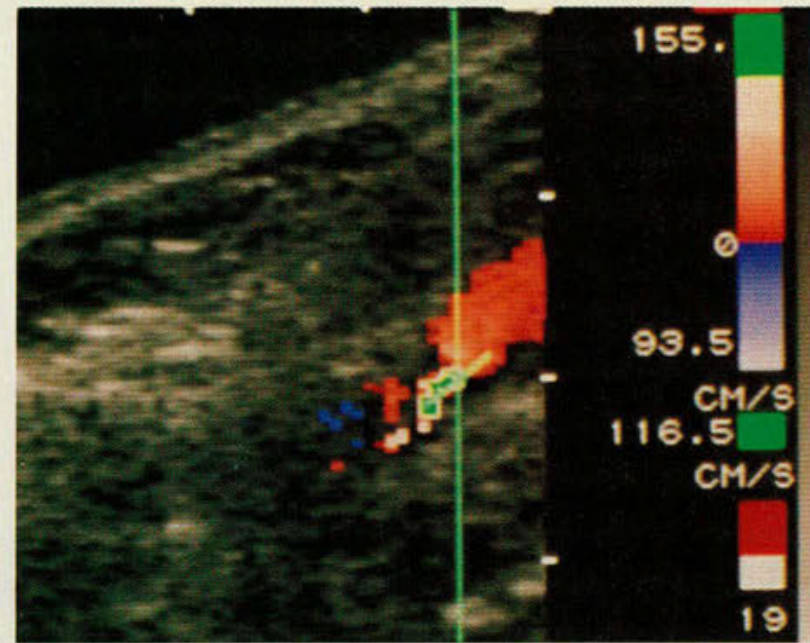

Fig 2. High-grade stenosis of internal carotid artery. The paler shade of color (green) indicates the jet. The spectral analysis displayed graphically below the image and localized by the range gait demonstrates markedly elevated velocity of flow during both systole and diastole.

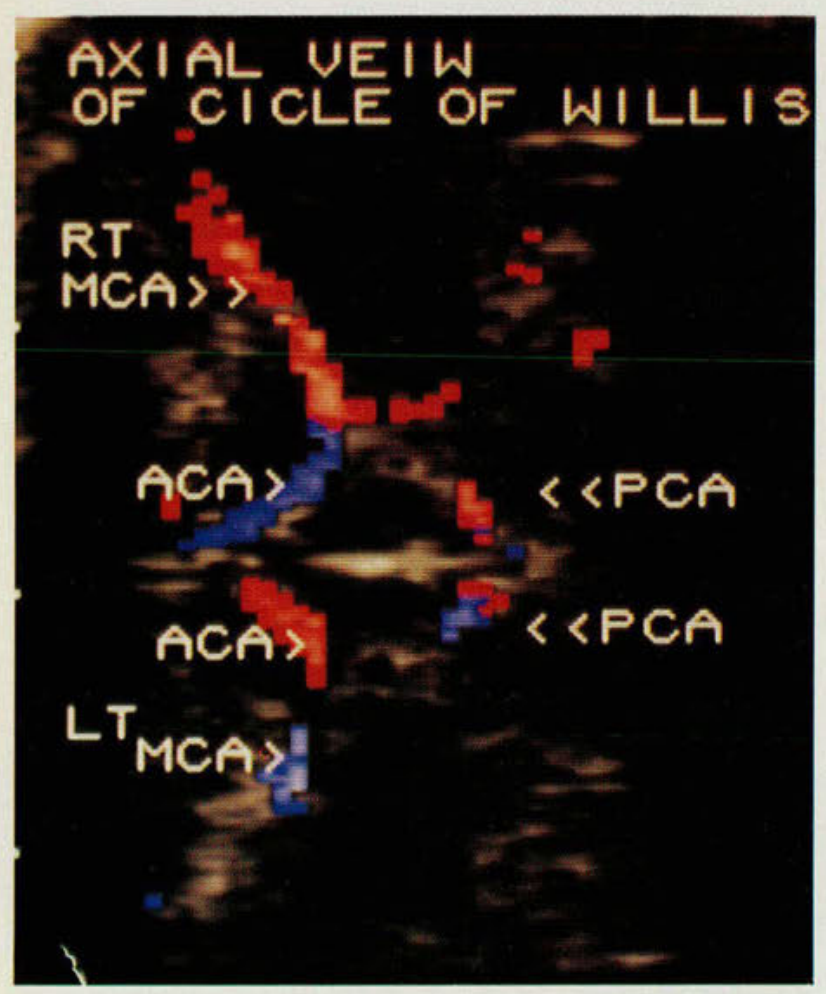

Fig 3. As obtained through the anterolateral fontanelle, normal color flow depiction of the neonate's circle of Willis. ACA, MCA, and PCA stand for anterior, middle, and posterior cerebral artery, respectively.

\section{Cerebrovascular imaging}

Adult. The next most common use of CDI is evaluation of flow in the carotid arteries. ${ }^{7,8}$ With CDI, the flow patterns at such complex anatomic regions as the carotid bifurcation (Fig 1) are better identified, as are alterations produced by plaque, stenosis,

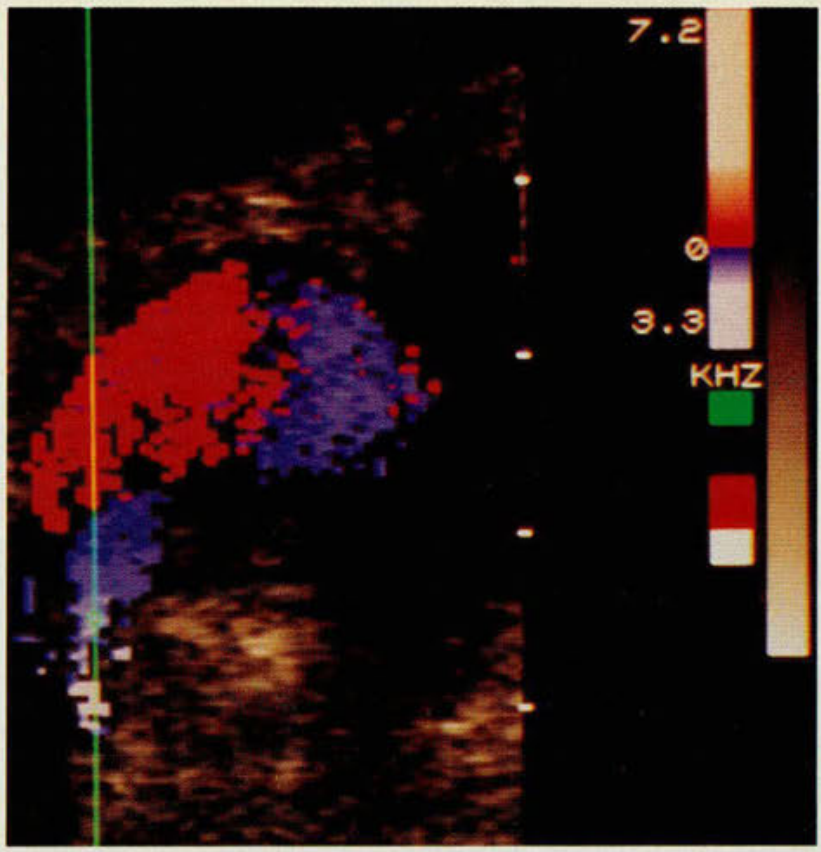

Fig 4. Doppler spectrum illustrated below the image of the neck of pseudoaneurysm shows the characteristic to-and-fro wave form. The image was obtained during diastole.

and ulceration. A "jet" (area of most rapid flow) at a region of clinically significant stenosis can be identified (Figs 2-3).

In addition, the time required to obtain spectra from pathologic areas may be reduced. Enhancing flow within the vessel lumen improves visualization of hypoechoic plaque, which may be difficult to see on conventional images.

Neonatal. Through the anterior fontanelle or squamous portion of the temporal bone, real-time, two-dimensional, color images of the circle of Willis can be obtained (Fig 3), and altered flow patterns can be identified. 9,10

The circle of Willis has been studied in infants undergoing extracorporeal membrane oxygenation (ECMO) because of severe respiratory insufficiency. A form of cardiopulmonary bypass, ECMO requires access to the aorta, which is achieved by cannulation and eventual ligation of the right common carotid artery. Perfusion of the right side of the cerebrum depends on adequate collateral circulation from the circle of Willis. CDI can determine if flow is present and whether left carotid cannulation would be preferable for certain infants.

\section{Peripheral arterial and venous imaging}

Flow within the subclavian, axillary, and femoral arteries, as well as their main branches, can be imaged. We have found CDI helpful in the diagnosis of perivascular hematomas, which appear as 


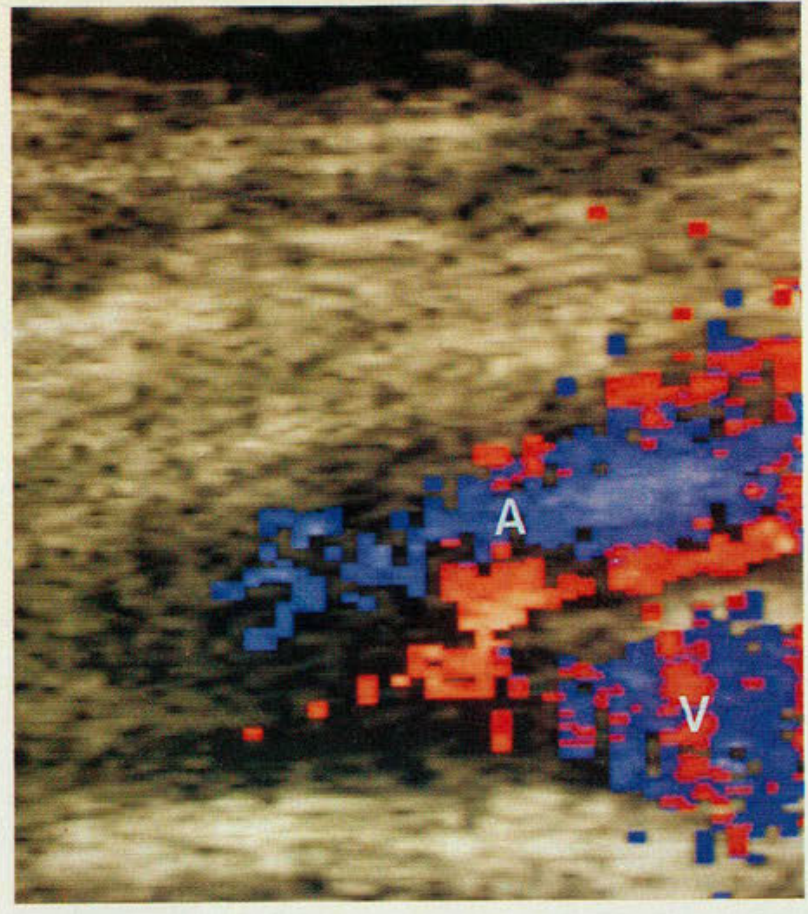

Fig 5. Arteriovenous fistula of the common femoral artery (A) and vein (V). Flow in the vein is turbulent, with a disordered mixture of red and blue color, which indicates tissue vibration (bruit).

well-circumscribed hypoechoic areas without flow, pseudoaneurysms, arteriovenous fistulas, and thrombi. The neck of a pseudoaneurysm can be localized readily.

A distinct color flow pattern consisting of rapid flow entering the pseudoaneurysm during systole and moderate flow exiting through diastole (Fig 4) is seen. This results in a unique to-and-fro wave form that is diagnostic of pseudoaneurysm ${ }^{11,12}$ (Fig 4).

A distinct color flow pattern, including visual depiction of a bruit, has been demonstrated in arteriovenous fistulas. ${ }^{13}$ This consists of a diffuse pulsatile mixture of red and blue pixels within the vessel, which represents complex, disorganized flow. This pattern extends into the soft tissues, which indicates vibration of perivascular tissues, the CDI equivalent of a bruit. Turbulent, semipulsatile flow has been noted in the veins that drain the arteriovenous fistula (Figs 5,6).

In peripheral venous imaging, CDI has been an effective modality for the diagnosis of deep venous thrombosis. Diagnosis is made by demonstration of intralumenal echoes, noncompressibility of the vein, lack of color flow, and a persistent filling defect when flow is augmented by distal compression. ${ }^{14}$ It is likely that the CDI will replace venography as the primary method for diagnosing deepvein thrombophlebitis (Figs 7,8).

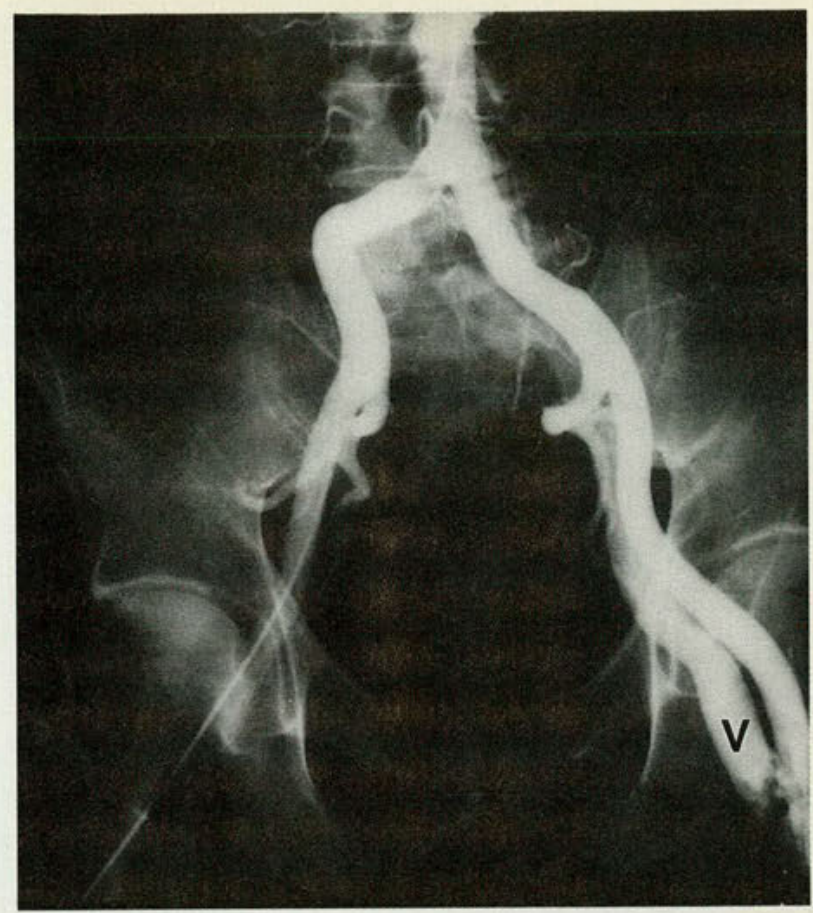

Fig 6. Correlative angiogram demonstrates retrograde venous flow in the left common femoral vein (V) through the arteriovenous fistula during the arterial phase.

\section{Major abdominal vessels imaging}

The flow pattern in abdominal aortic aneurysm can be better characterized with CDI, and hypoechoic clots can be delineated more reliably. Using this method, aortic dissection also can be depicted without the use of an invasive procedure ${ }^{15}$ Patency of the inferior vena cava or, if present, thrombus within the lumen also can be documented. The renal arteries and veins often can be identified and their flow evaluated, thus improving on the conventional duplex Doppler diagnosis of vascular compromise.

\section{Portal and hepatic imaging}

With CDI, it is possible to visualize normal and disturbed flow as well as vascular patency or lesions within the vessels of the portal and hepatic systems. Alterations secondary to portal hypertension can be depicted, and collateral circulation can be seen. ${ }^{3}$ Complications such as cavernous transformation of the portal vein have been identified. Unusual complications of invasive procedures, such as portohepatic venous fistula, also have been detected using CDI. ${ }^{16}$

\section{Tumor imaging}

Arteriovenous shunting within neoplasms has been detected using both conventional duplex Doppler ultrasonography ${ }^{17}$ and CDI. ${ }^{18}$ Flow patterns of neo- 


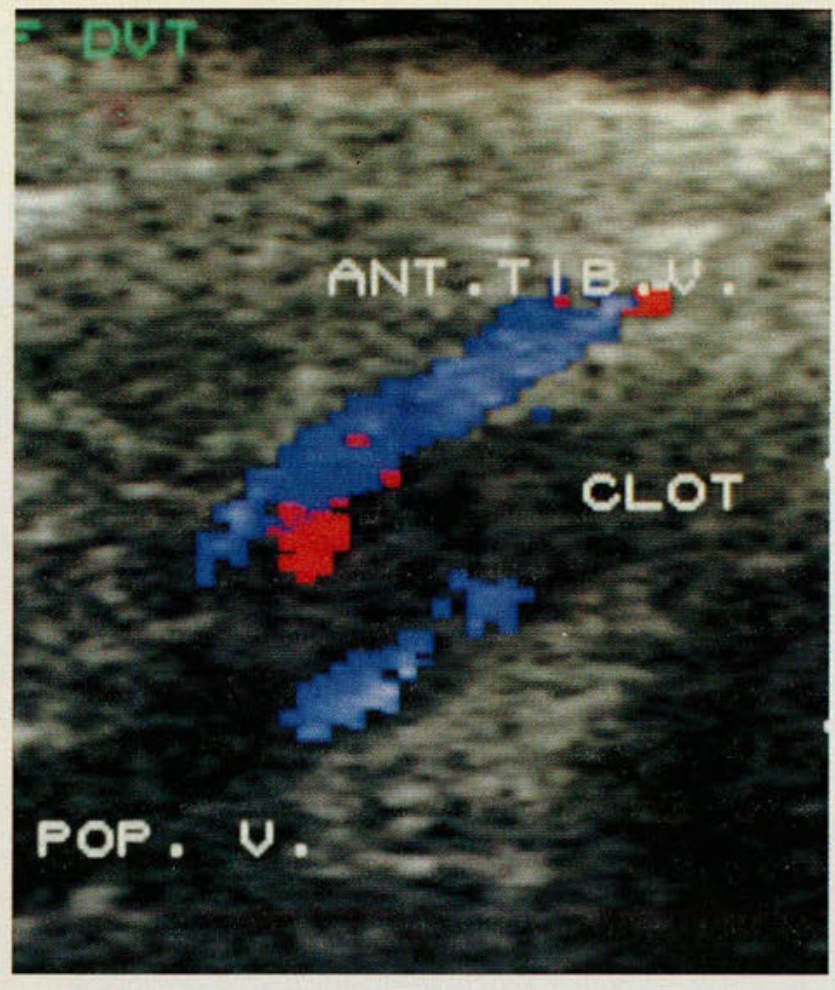

Fig 7. Normal flow demonstrated in blue in the anterior tibial vein. There is evidence of clot within the proximal posterior tibial vein and distal popliteal vein (POP). Evidence of some color flow is noted within the proximal posterior tibial vein, with distal augmentation.

plastic vascularity may help in characterizing malignant tumors. Further study is needed, however, to determine the clinical utility of this application.

\section{Obstetric imaging}

CDI involves less ultrasound exposure than conventional duplex Doppler imaging. Although this application is still investigational, CDI may prove to be beneficial in evaluating placental well-being. It is possible that regional placental abnormalities may be identified with this technique. Research to evaluate fetal vascular flow in the major vessels is under way.

\section{Comment}

There are a few limitations to CDI. One is gasfilled bowel, which will produce artifacts during abdominal examinations. Reductions in gray-scale quality or frame rate may sometimes be necessary to obtain better color images. Despite these problems, with improving technology and equipment, CDI should improve the diagnostic capability of duplex Doppler ultrasonography because of CDI's direct demonstration of flow. It should expand the role of diagnostic ultrasonography and create new applications of noninvasive imaging.

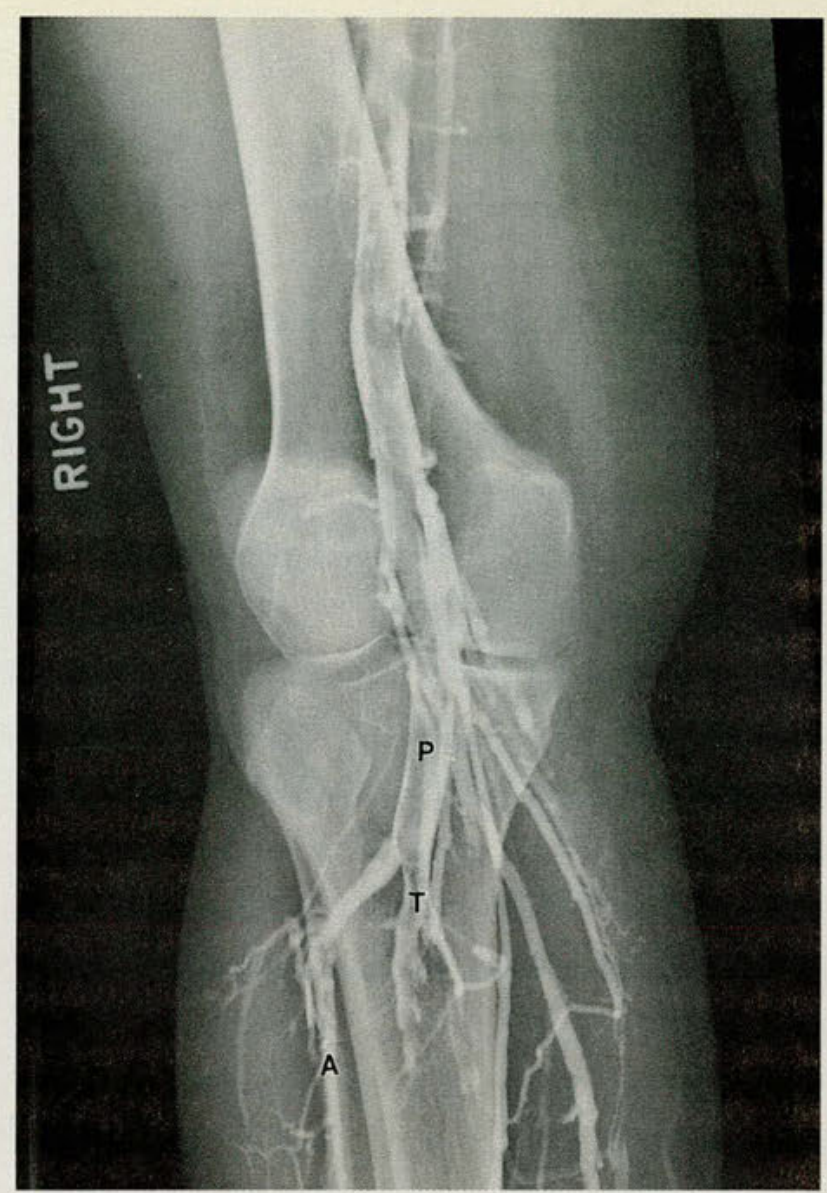

Fig 8. Clot is well demonstrated on the correlative venogram within the popliteal vein $(P)$ and proximal posterior tibial vein (T). (The posterior tibial vein bifurcation is not seen.) Normal flow is seen in the anterior tibial vein $(A)$.

\section{Summary}

Color Doppler imaging is a new advance in ultrasonography. It allows simultaneous two-dimensional imaging of structure and blood flow without the need for invasive procedures or intravascular contrast, in most cases.

1. Bommer WJ, Miller L: Real-time two-dimensional color flow Doppler: Enhanced Doppler flow imaging in the diagnosis of cardiovascular disease, abstract. Am J Cardiol 1982;49:944.

2. Namekawa K, Kasai C, Tsukamoto M, et al: Imaging of blood flow using autocorrelation. Ultrasound Med Biol 1982;8:138.

3. Merritt CRB: Doppler color flow imaging. JCU 1987;15:591-597.

4. Omoto R: Color Atlas of Real-time Two-dimensional Doppler Echocardiography. Tokyo, Shindan-To-Chiryo Co, Ltd, 1984.

5. Suzuki Y, Kambara H, Kadota K, et al: Detection of intracardiac shunt flow in atrial septal defect using a real-time two-dimensional colorcoded imaging system and comparison with contrast two-dimensional echocardiography. Am J Cardiol 1985;56:347-350.

6. Middleton WD, Foley WD, Lawson TL: Color-flow Doppler imaging of carotid artery abnormalities. AJR 1988;150:419-425.

7. Middleton WD, Foley WD, Lawson TL: Flow reversal in the normal carotid bifurcation: Color Doppler flow imaging analysis. Radiology 1988;167:207-210.

8. Ortiz E, Robinson PJ, Deanfield JE, et al: Localization of ventricular septal defects by simultaneous display of superimposed color Doppler 


\section{THE FIRST HYPOALLERGENIC FORMULA MADE FROM HYDROLYZED WHEY PROTEIN}

Because of increasingly recognized sensitivity to soy, ${ }^{1}$ Carnation has developed Carnation $\circledast$ GOOD START H.A. ${ }^{\mathrm{TM}}$ It effectively resolves symptoms in infants suffering from formula intolerance or milk allergy, and may prevent allergic manifestations in infants with a family history of allergy.

When atopic infants were fed the GOOD START H.A. formulation, four clinical studies showed a $0 \%$ reaction rate, ${ }^{2-5}$ and one study showed a $3.6 \%$ reaction rate. ${ }^{6}$

No curd formation and rapid gastric emptying, make GOOD START H.A. easy to digest and may cause less spitting up. The whey base makes it a high-quality protein source for optimal growth. And, parents will like the pleasant taste and aroma, as well as the competitive price for long-term use. GOOD START H.A. is available in easy-to-dissolve powder in 12-oz. cans.

The GOOD START H.A. formulation has been thoroughly researched in clinical trials and safely fed to more than 25,000 infants over the past 3 years in Europe. 


\section{INSTEAD OF SOY, RECOMMEND GOOD START H.A. FOR:}

\section{Formula Intolerance}

Resolves symptoms of milk allergy or intolerance such as spitting up, skin rash, runny nose, and colic

\section{Routine Feeding of Atopic Infants}

May prevent allergic manifestations in infants with a family history of allergy ${ }^{2}$

\section{Routine Feeding of Normal Infants}

Nutritionally complete for optimal growth and development

\footnotetext{
References:

1. Committee on Nutrition, American Academy of Pediatrics: Pediatric Nutrition Handbook, ed 2, Forbes GB, Woodruff CW (eds). Elk Grove Village, III, American Academy of Pediatrics, 1985, p 210.

2. Vandenplas Y, Deneyer M, Sacre L, et al: Preliminary data on a field study with a new hypo-allergic formula. EurJ Pediatr, to be published.

3. Kahn A, Rebuffat E, Blum D, et al: Difficulty in initiating and maintaining sleep associated with cow's milk allergy in infants. Sleep 1987:10:116-121.

4. Zabransky S, Zabransky M: Preliminary clinical experience with a hypoallergenic infant formula. Extracta Paediatrica 1987;11:10-22.

5. Schmidt E, Reinhardt D, Gerke R: The use of hypoallergenic milk formulas in newborns. Der Kinderarzt 1987:5:627-631.

6. Denis R, Willème D: Data on file, Carnation Co.
}

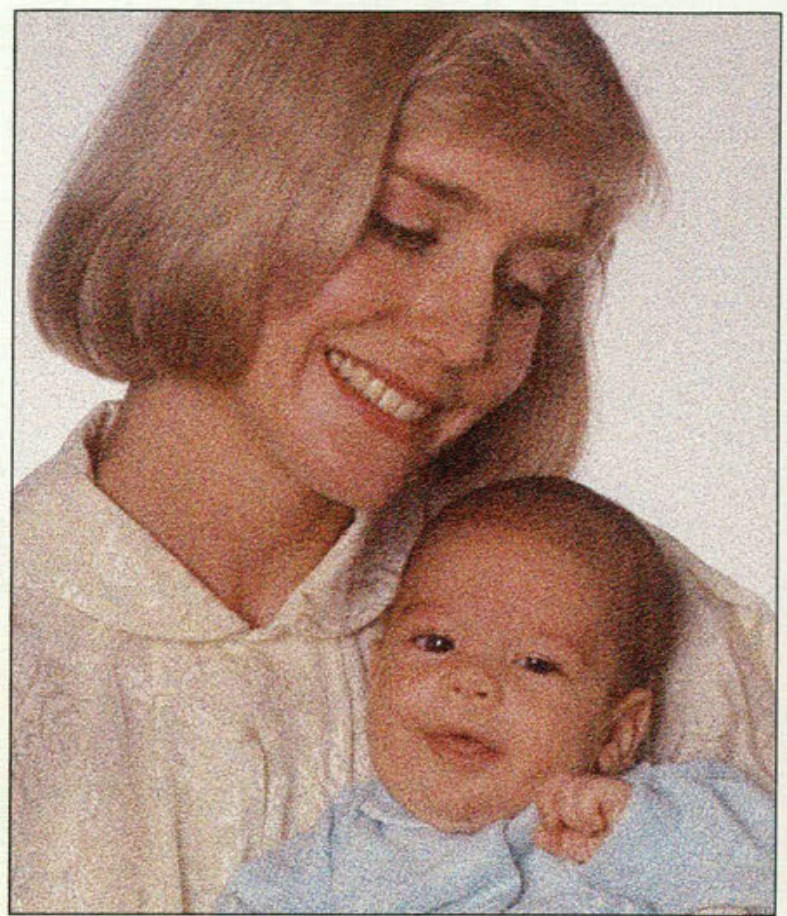

COMPLETE NUTRITIONAL INFORMATION INGREDIENTS: $42 \%$ ENZYMATICALLY HYDROLYZED REDUCED MINERALS WHEY AND WHEY PROTEIN CONCENTRATE, 24\% VEGETABLE OILS (PALM OLEIN, HIGH-OLEIC SAFFLOWER AND COCONUT), $17 \%$ MALTODEXTRIN, $14 \%$ LACTOSE, $1 \%$ LECITHIN, AND LESS THAN $1 \%$ OF EACH OF THE FOLLOWING: CALCIUM CHLORIDE, POTASSIUM CHLORIDE, POTASSIUM CITRATE, CALCIUM PHOSPHATE, CHOLINE BITARTRATE, SODIUM ASCORBATE (VITAMIN C), SALT, MAGNESIUM CHLORIDE, TAURINE, FERROUS SULFATE (IRON), INOSITOL, ZINC SULFATE, L-CARNITINE, ALPHA TOCOPHERYL ACETATE (VITAMIN E), NIACINAMIDE, CALCIUM PANTOTHENATE, COPPER SULFATE, RIBOFLAVIN, VITAMIN A ACETATE, PYRIDOXINE HYDROCHLORIDE (VITAMIN B6) THIAMINE MONONITRATE, FOLIC ACID, PHYLLOQUINONE (VITAMIN K), POTASSIUM IODIDE, VITAMIN D3, MANGANESE SULFATE, BIOTIN, VITAMIN B12.

NOTE: CONTAINS LACTOSE.

Call toll-free 1-800-628-BABY (2229) to request samples, or for more information write to: Carnation Nutritional Products 5045 Wilshire Blvd, Los Angeles, CA 90036.

\begin{tabular}{|c|c|c|c|c|c|c|}
\hline $\begin{array}{l}5 \mathrm{fl} \mathrm{oz} \text { Provides } 100 \text { Calories, } \\
\text { Prepared As Directed }\end{array}$ & $\begin{array}{l}\text { Per } 10 \\
\text { Caloric }\end{array}$ & & $\begin{array}{c}\text { Caloric } \\
\text { Distribution }\end{array}$ & & \multicolumn{2}{|c|}{$\begin{array}{l}\text { Per } 100 \\
\text { Calories }\end{array}$} \\
\hline NUTRIENTS: & & & & VITAMIN C & & \\
\hline PROTEIN & & $\mathrm{g}$ & $9.8 \%$ & (Ascorbic Acid) & 8 & $\mathrm{mg}$ \\
\hline FAT & 5.1 & $\mathrm{~g}$ & $46.0 \%$ & CHOLINE & 12 & $\mathrm{mg}$ \\
\hline CARBOHYDRATE & 11 & $g$ & $44.2 \%$ & INOSITOL & 6.1 & $\mathrm{mg}$ \\
\hline WATER & 135 & $\mathrm{~g}$ & & MINERALS: & & \\
\hline LINOLEIC ACID & 450 & $\mathrm{mg}$ & & CALCIUM & 64 & $\mathrm{mg}$ \\
\hline VITAMINS: & & & & PHOSPHORUS & 36 & $\mathrm{mg}$ \\
\hline VITAMIN A & 300 & IU & & MAGNESIUM & 6.7 & $\mathrm{mg}$ \\
\hline VITAMIN D & 60 & IU & & IRON & 1.5 & $\mathrm{mg}^{*}$ \\
\hline VITAMIN E & 1.2 & IU & & ZINC & 0.75 & $5 \mathrm{mg}$ \\
\hline VITAMIN K & 8.2 & mcg & & MANGANESE & 7 & $\mathrm{mcg}$ \\
\hline THIAMINE (Vitamin B1) & 60 & mcg & & COPPER & 80 & $\mathrm{mcg}$ \\
\hline RIBOFLAVIN (Vitamin B2) & 135 & $\mathrm{mcg}$ & & IODINE & 8 & $\mathrm{mcg}$ \\
\hline VITAMIN B6 & 75 & $\mathrm{mcg}$ & & SODIUM & 24 & $\mathrm{mg}$ \\
\hline VITAMIN B12 & 0.22 & $\mathrm{mcg}$ & & POTASSIUM & 98 & $\mathrm{mg}$ \\
\hline NIACIN & 750 & $\mathrm{mcg}$ & & CHLORIDE & 59 & $\mathrm{mg}$ \\
\hline FOLIC ACID (Folacin) & 9 & $\operatorname{mcg}$ & & OTHERS: & & \\
\hline PANTOTHENIC ACID & 450 & $\mathrm{mcg}$ & & L-CARNITINE & 10 & $\mathrm{mg} / \mathrm{qt}$ \\
\hline BIOTIN & 2.2 & $\operatorname{mcg}$ & & TAURINE & 50 & $\mathrm{mg} / \mathrm{qt}$ \\
\hline
\end{tabular}

-The addition of iron to this formula conforms to the recommendation of the Committee on Nutrition of the American Academy of Pediatrics. 
and cross sectional echocardiographic images. Br Heart $J$ 1985;54:5360.

9. Grant EG, White EM, Schellinger D, et al: Cranial duplex sonography of the infant. Radiology 1987;163:177-185.

10. Perlman JM, Goodman S, Kreusser KL, et al: Reduction in intraventricular hemorrhage by elimination of fluctuating cerebral blood flow velocity in preterm infants with respiratory distress syndrome. $N \mathrm{Engl}$ J Med 1985;312:1353-1357.

11. Kreipke DL, Holden RW, Wass JL: Two angiographic signs of pseudoaneurysm: Systolic jet and diastolic washout. Radiology 1982;144:7982.

12. Mitchell DG, Needleman L, Bezzi M, et al: Femoral artery pseudoaneurysm: Diagnosis with conventional duplex and color Doppler US. Radiology 1987;165:685-690.

13. Igidbashian VN, Mitchell DG, Needleman L, et al: Color Doppler imaging of iatrogenic femoral arterial injuries. Presented at Association of University Radiologists annual meeting, New Orleans, 1988.
14. Barnes RW: Doppler technique for lower-extremity venous disease, in Zwiebel WJ (ed.): Introduction to Vascular Ultrasonography, ed 2. New York, Grune \& Stratton, Inc, 1986, pp 333-350.

15. Dagli SV, Nanda NC, Roitman D, et al: Evaluation of aortic dissection by Doppler color flow mapping. Am J Cardiol 1985;56:497-498.

16. Bezzi M, Mitchell DG, Neddleman L, et al: Iatrogenic aneurysmal portohepatic venous fistula: Diagnosis by color Doppler imaging. $J$ Ultrasound Med 1988;7:457-461.

From the Department of Radiology, Division of Ultrasound, Thomas Jefferson University Hospital, Philadelphia.

Reprint requests to Dr Igidbashian, 113 Foster Ave, Havertown, PA 19083. 


\section{NEW300 mg CAPSULES}




\section{FOR SERIOUS INFECTIONS}

\section{Clinically effective in serious polymicrobial infections involving Bacteroides fragilis and}

other important anaerobes, staphylococci, streptococci, and pneumococci. Follow-up therapy to CLEOCINIV, or initial therapy when clinically appropriate.

Positive penetration profile. CLEOCIN HCl is rapidly and predictably absorbed, rapidly penetrates most body tissues and fluids, including bone and pus. Food does not significantly affect absorption.

\section{Not a beta-lactam. No cross-allergenicity with} penicillins or cephalosporins. However, maculopapular rash and urticaria have been observed during therapy with CLEOCIN.

CLEOCIN is generally well tolerated. Like many other antibiotics, however, it has been associated with Clostridium difficile colitis. Available evidence does not suggest a relationship to dosage or route of administration.

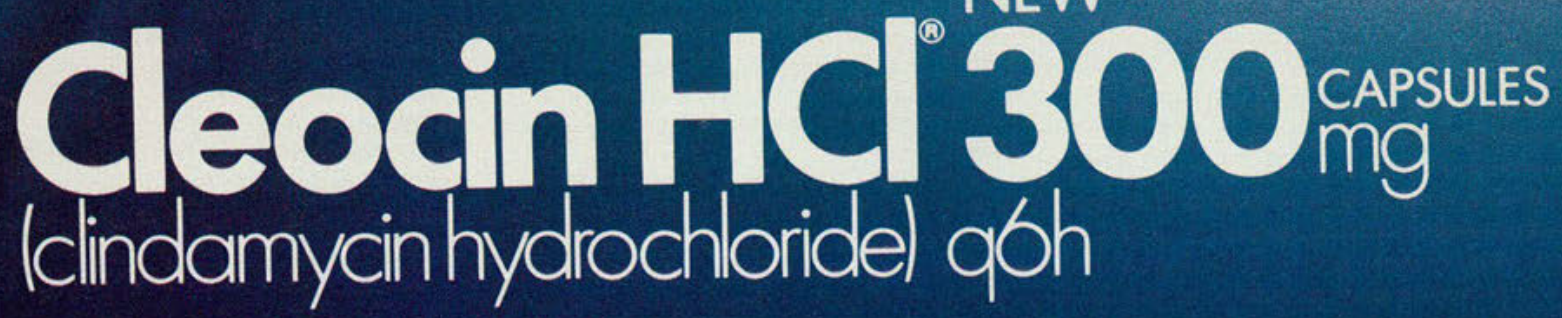

Please see adjacent page for brief summary of prescribing information.

\section{Upjohn}

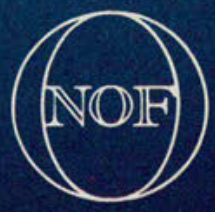




\section{FOR SERIOUS INFECTIONS: NEW Cleocin HC 300 ispars}

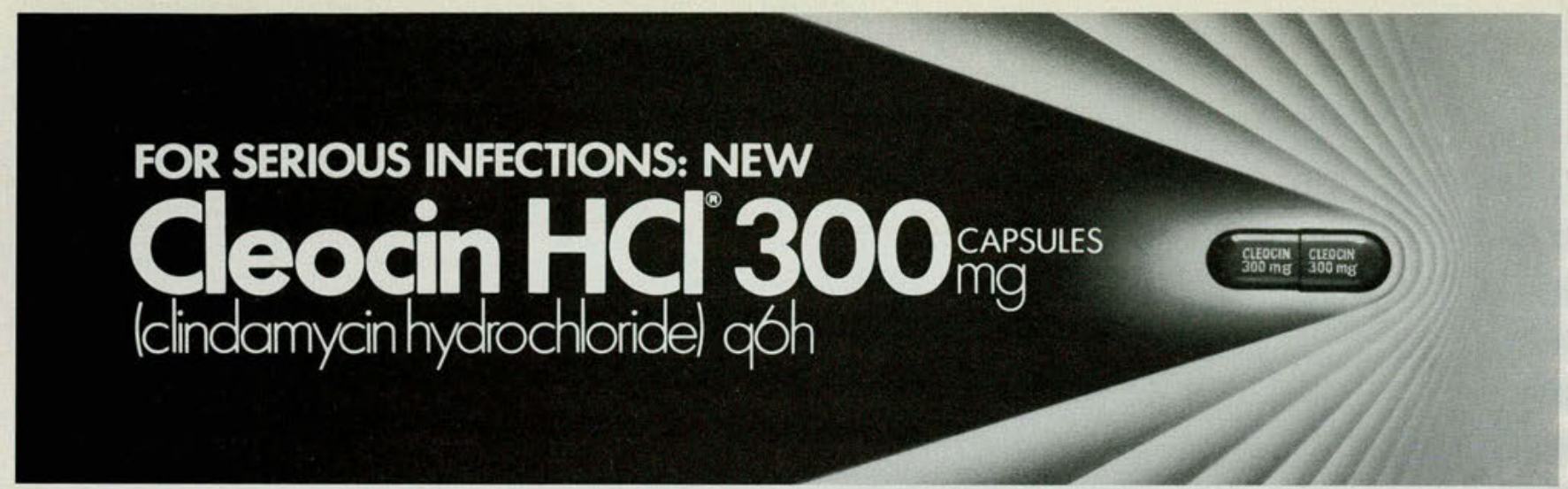

CLEOCINPHOSPHATE* Sterile Solution CLEOCINHCl ${ }^{\circ}$ Capsules (clindamycin)

\section{WARNING}

Clindamycin therapy has been associated with severe colitis which may end fatally. Therefore, it should be reserved for serious infections where less toxic antimicrobial agents are inap propriate, as described in the Indications Section. It should not be used in patients with nonbacterial infections, such as most upper respiratory tract infections. Studles indicate a toxin(s) produced by Clostridia is one primary cause of antibiotic associated colitis.

Cholestyramine and colestipol resins have been shown to bind the toxin in vitro. See WARNINGS section. The colitis is usually characterized by severe, persistent diarrhea and severe abdominal cramps and may be associated with the passage of blood and mucus. Endoscopic examination may reveal pseudomembranous colitis. Stool culture for Clostridium difficile and stool assay for C. difficile toxin may be helpful diagnostically. When significant diarrhea occurs, the drug should be discontinued or, if necessary, continued only with close observation of the patient. Large bowel endoscopy has been recommended

Antiperistaltic agents such as opiates and diphenoxylate with atropine (Lomotil) may prolong and/or worsen the condition. Vancomycin has been found to be effective in the treatment of antibiotic associated pseudomembranous colitis produced by Clostridium difficile. The usual adult dose is 500 milligrams to 2 grams of vancomycin orally per day in three to four divided doses administered for 7 to 10 days. Cholestyramine or colestipol resins bind vancomycin in vitro. If both a resin and vancomycin are to be administered concurrently, it may be advisable to separate the time of administration of each drug.

Diarrhea, colitis, and pseudomembranous colitis have been observed to begin up to several weeks following cessation of therapy with clindamycin

\section{INDICATIONS}

Serious infections caused by susceptible anaerobic bacteria. Patients with serious infections due to susceptible strains of streptococci, pneumococci, and staphylococci in whom its use should be reserved for penicillin-allergic patients or other patients for whom, in the judgment of the physician, a penicillin is inappropriate.

Consider the nature of the infection and the suitability of less toxic alternatives (e.g., erythro mycin). Bacteriologic studies should be performed to determine the causative organisms and their susceptibility to clindamycin.

\section{CONTRAINDICATIONS}

History of hypersensitivity to clindamycin or lincomycin.

\section{WARNINGS}

See WARNING box. A toxin produced by

Clostridia is one primary cause of antibiotic associated colitis. Cholestyramine and colestipol resins have been shown to bind the toxin in vitro. Mild cases of colitis may respond to drug discontinuance alone. Moderate to severe cases should be managed promptly with fluid, electrolyte and protein supplementation as indicated. Vancomycin has been found to be effective in the treatment of antibiotic associated pseudomembranous colitis produced by C. difficile. The usual adult dosage is $500 \mathrm{mg}$ to 2 grams of vancomycin orally per day in 3 or 4 divided doses for 7 to 10 days. Systemic corticoids and corticoid retention enemas may help relieve the colitis. Other causes of colitis should also be considered

A careful inquiry should be made concerning previous sensitivities to drugs and other allergens. Usage in Pregnancy: Safety has not been established. Usage in Newborns and Infants: Appropriate monitoring of organ system functions is desirable. CLEOCIN PHOSPHATE contains benzyl alcohol which has been associated with a fatal gasping syndrome in infants. Nursing Mothers: Clindamycin has been reported to appear in breast milk in ranges of 0.7 to $3.8 \mathrm{mcg} / \mathrm{ml}$. Usage in Meningitis: Since clindamycin does not diffuse adequately into the cerebrospinal fluid, it should not be used to treat meningitis.

Antagonism has been demonstrated between clindamycin and erythromycin in vitro. Because of possible clinical significance, these two drugs should not be administered concurrently.

SERIOUS ANAPHYLACTOID REACTIONS REQUIRE IMMEDIATE EMERGENCY TREATMENT WITH EPINEPHRINE. OXYGEN AND IN TRAVENOUS CORTICOSTEROIDS SHOULD ALSO BE ADMINISTERED AS INDICATED.

\section{PRECAUTIONS}

Older patients with associated severe illness may tolerate diarrhea less well. When clindamycin is indicated in these patients, they should be carefully monitored for change in bowel frequency. Prescribe with caution in individuals with a history of gastrointestinal disease, particularly colitis and also in atopic individuals. Indicated surgical procedures should be performed in conjunction with therapy. Patients with very severe renal and/or hepatic disease accompanied by severe metabolic aberrations should be dosed with caution and serum clindamycin levels monitored during high dose therapy

During prolonged therapy, periodic liver, and kidney function tests and blood counts should be performed. Use may result in overgrowth of nonsusceptible organisms, particularly yeasts. Clindamycin has neuromuscular blocking properties and may enhance other neuromuscu lar blocking agents. Use with caution in patients receiving such agents. Do not inject clindamycin IV undiluted as a bolus. Dilute prior to IV administration to $300 \mathrm{mg}$ per $50 \mathrm{ml}$ or more of diluent. Infuse over at least 10-60 minutes. (See Dosage and Administration.) CLEOCIN HCl Capsules $75 \mathrm{mg}$ and $150 \mathrm{mg}$ contain FD\&C Yellow No. 5 (tartrazine) which may cause allergic-type reactions (including bronchial asthma) in certain susceptible individuals, especially in patients who also have aspirin hypersensitivity.

\section{ADVERSE REACTIONS}

Gastrointestinal: Abdominal pain, nausea, vomiting and diarrhea. (See WARNING box.) An unpleasant or metallic taste has been reported with high doses.

Hypersensitivity Reactions: Maculopapular rash and urticaria. Generalized mild to moderate morbilliform-like skin rashes are the most frequent adverse reactions. Rare instances of erythema multiforme, some resembling Stevens-Johnson syndrome, have been reported. A few cases of anaphylactoid reactions have been reported. If a hypersensitivity reaction occurs, the drug should be discontinued. The usual agents should be available for emergency treatment. Liver: Jaundice and abnormalities in liver function tests have been observed. Hematopoietic: Neutropenia, eosinophilia agranulocytosis and thrombocytopenia have been reported; no direct etiologic relationship to concurrent clindamycin therapy has been made. Local Reactions: Pain, induration and sterile abscess have been reported after intramuscular injection and thrombophlebitis after intravenous infusion. Reactions can be minimized or avoided by giving deep intramuscular injections and avoiding prolonged use of indwelling intravenous catheters. Musculoskeletal: Rare instances of polyarthritis have been reported. Cardiovascular: Rare instances of cardiopulmonary arrest and hypotension have been reported following too rapid IV infusion. (See Dosage and Administration.) Renal: Renal dysfunction with azotemia, oliguria, proteinuria has rarely been observed. No direct relationship has been established.

\section{DIRECTIONS FOR DISPENSING}

Pharmacy Bulk Package-Not for Direct Infusion The Pharmacy Bulk Package is for use in a Pharmacy Admixture Service only under a laminar flow hood. Entry into the vial should be made with a small diameter sterile transfer set or other small diameter sterile dispensing device, and contents dispensed in aliquots using aseptic technique. Multiple entries with a needle and syringe are not recommended. AFTER ENTRY USE ENTIRE CONTENTS OF VIAL PROMPTLY. ANY UNUSED PORTION MUST BE DISCARDED WITHIN 24 HOURS AFTER INITIAL ENTRY

\section{HOW SUPPLIED}

Available as sterile solution with each m

containing clindamycin phosphate equivalent to

$150 \mathrm{mg}$ clindamycin base. Vials of 2, 4, and $6 \mathrm{~mL}$

Vials of $600 \mathrm{mg}$ and $900 \mathrm{mg}$ are available in ADD-Vantage ${ }^{\text {TM }}$ Vial system

$1.60 \mathrm{ml}$ Pharmacy Bulk Package.

CLEOCIN HCl as $75 \mathrm{mg}, 150 \mathrm{mg}$, and $300 \mathrm{mg}$ capsules.

Caution: Federal law prohibits dispensing without prescription.

$A D D$-Vantage is a registered trademark

of Abbott Laboratories

For additional product information see your Upjohn representative

Upjohn The Upjohn Company July 1988 Kalamazoo MI 4900 